\title{
The International Congress of Leprosy E. Muir.
}

The Congress held in Cairo from the 21 st till the 27 th of March was in many ways unique. It is 15 years since the last International Conference; and this is the first time that the Governments of all countries that are concerned in any way with leprosy have been invited by the country acting. as host to send official delegates. These invitations met with a most satisfactory response, no fewer than fifty countries being officially representecl.

In August, 1935, a meeting of the Council of the International Leprosy Association was called in London. Only four members were able to attend, and as one of these, Dr. Wade, was in the hands of the surgeon, the meetings were held in his room in a nursing home. Another of those who attended had to leave before the end to undergo an operation. In spite of these initial difficulties it was agreed that the time was becoming ripe for an international meeting of leprologists, and 1938 was provisionally fixed for the event, Egypt being suggested as the venue. Subsequent correspondence with the other members of Council confirmed this decision and the Government of Egypt responded generously, not only giving their hospitality, but offering to organise the Congress under the patronage of H.M. King Farouk.

A strong Committee was formed with the Minister of Public Health as Presiclent. and Prof. Khalil Bey as Secretary, ably assisted by Dr. Dalgamouni. This Committee made all arrangements for conducting the Congress. It also made lavish provision for social entertainments and for visits to scientific institutions and places of general and scientific interest. 
The scientific sicle was fittingly (lelegated to a committee composed of the Conncil and officials of the International Leprosy Association.

Another unicue feature of the Cairo Congress was the method of its (leliberations. At the previous international conferences papers had been read and discussed in $f u l l$ session. It was realised that, valuable as such a method of presentation and (liscussion of the problems of leprosy may be, real advance towards agreement can only be attained by small carefully selected groups meeting together and thrashing out the points at issue. This method had been used with signal success at the representative conference held in the Philippines in 1931, uncler the auspices of the American Leprosy Founclation.

With this in view four sub-committees were appointed, their respective subjects being: classification, treatment, endemiology and control, and in aitro cultivation of $M$. lepra. Care was taken to see that on each committee opposing viewpoints should be represented. The objects in view were, (a) to reach as far as possible agreement on matters in (lispute: and (b) failing agreement, to formulate common methods of procedure along which all could work, and common methods of record which would make it possible to compare results obtained in different places. In spite of the shortness of time available satisfactory progress was made, and the lines have been clarified along which concerted action should be taken in the next five years, at the end of which time it is proposed to hold the next Congress. Resolutions based upon the reports of the first three sub-committees were put forward by the Resolutions sub-committee and adopterl by the Congress. Arrangements have been made for the immediate publication of these resolutions, and they will appear later, along with the papers read at the Congress and the (liscussions, in a publication which will be issued by the Government of Egypt.

The papers read at the Congress were divided into six sections, one whole session being levoted to each. These sections comprised: A. Geographical Distribution and Ejpi(lemiology ; B. Clinical Types and Classification : C. Research, including Cultivation and Inoculation of the Leprosy Organism; D. Treatment; E. Methools of Control: F. Miscellaneous, including Rat and Buffalo Leprosy.

Among the many aspects of interest and importance raised, a few may be mentioned which attracted particular attention.

Perhaps the most outstanding of these was the much 
(liscussed clifference between the two main types of leprosy. In this connection it may be mentioned that the term "cutaneous," as applied to one of these types, has been (lefinitely abandoned in favour of the term "lepromatous." There is general agreement that the lepromatous type of lesion differs widely from the neural, and especially from the tuberculoid. This difference extends to all aspects of leprosy. The clinical and histological pictures are distinct: the prognosis is much more favourable in the tuberculoid; the lines of treatment differ in the two types, as do also the methods of control. The tuberculoid type of lesion, at first supposed to be confined to one or two countries, is now recognised to have a much wider (listribution; it may, in fact, be the commonest type.

Under treatment, the primary importance of general physical improvement was again emphasised. It is recognised that the principal predisposing causes may vary in different places, also that the disease may take on a more severe form and be less amenable to treatment than in others, though whether this is due to psychological, sociological $\mathrm{Or}^{\circ}$ economic differences is not yet clearly determined.

The oils of the various chaulmoogra or hydnocarpus species still hold first place under special treatment. Reports were given from various centres where better results had been obtained with larger doses of the oil or esters, as much as 20 c.c. or more being given subcutaneously per week. These larger doses are now made possible by the pure nature of the oil prepared from carefully selected seeds.

French workers reported promising results with a new preparation in the form of a combination of Chaulmoogra and Cholestrol which, in the form of a fine emulsion, is given intravenously.

One of the most important aspects of leprosy centred round methods of conducting leprosy surveys and recording results. The findings of the sub-committee on epidemiolog $y$ which dealt with this subject, should be of distinct value, and should gradually produce in coming years a harvest in the form of comparable reports from widely varying endemic countries. It may then become possible to determine whether leprosy is increasing or diminishing in any area surveyed, and what are the principal factors governing incidence.

Much interest was called forth by a paper read by Dr. Soule on in vitro culture of $M$. Lepre. He has now succeeded in carrying on a slow-growing culture through 60 series of subcultures. Controls with heated lepromatous 
material produced scanty numbers of organisms by "carry over" only to six subcultures. Ordinary medlia are used, but the results are apparently due to the carefully regulated pressure of oxygen and carbon clioxide under which the cultures are kept. Unfortunately other experienced workers who have used Soule's methods have so far failed to confirm his results.

Dr. Adler's paper on inoculation of splenectomised Syrian hamsters with $M$. lepre, and the microscopic slides he demonstrated, roused much interest. There seems little doubt that human leprosy has been transmitted successfully to these animals and that the bacilli have multiplied considerably. It is still too soon to know whether progressive disease will result and whether the infection can be transmitted through successive series of animals. So far human leprosy has proved refractive to animal inoculation; and if human leprosy can be (leveloped in Syrian hamsters we may be able to gain light on some of the more obscure aspects of Hansen's bacillus, and it may be possible to test out more satisfactorily the effects of chemotherapy.

The Cairo Congress was the occasion of the first General Meeting of the International Leprosy Association. As many of our readers are aware, the formation of this Association was one of the important outcomes of the leprosy conference held in the Philippines in 1931. It includes in its membership leading leprologists throughout the world, and has clone much by means of its quarterly journal to co-ordinate effort in all countries where leprosy is a disease of importance. The publication of this first class journal is rendered possible through the generosity of the American Leprosy Foundation. The office bearers and Councillors of the International Leprosy Association are elected at five yearly intervals, and the following are those now in office:-

President: Dr. E. Marchoux.

Vice-Presidents : Western Section-Dr. P. Balina.

Eastern Section-Dr. J. Lowe.

General Secretary-Treasurer: Dr. E. Muir.

Councillors: Dr. E. Burnet.

Dr. Victor Heiser. (Liaison Officer).

Dr. $V$. Klingmuller.

Dr. P. Lampe.

Dr. B. Moiser.

Dr. M. Ota.

Dr. E. Rabello.

Dr. J. N. Rodriguez. 
Sir Leonard Rogers.

Dr. G. Ryrie.

Dr. N. Serra.

Dr. F. Sorel:

Dr. H. Warle. (ex-officio).

Editorial Board: Dr. H. Wade. (Editor).

Dr. J. L. Maxwell. (Associate Editor)

Dr. H. P. I.ie

Dr. E. Muir

Section Conncils.

Western Section._Chairman: Dr. I'. Balina.

Vice-Chairman :

Dr. H. C. (le Souza-Araujo.

Sec. Treas.: Dr. II. I’. Lie.

Councillors: Dr. 11. E. Hasseltine.

Sir Walter Johnson.

Dr. R. Briercliffe.

Eastern Section.-Chairman: Dr. J. Lowe.

Vice-Chairman: Dr. K. Mitsuda.

Sec. Treas.: Dr. J. L. Maxwell.

Councillors: Dr. R. G. Cochrane.

Dr. Gushue Taylor.

Dr. C. J. Austin.

The Congress provicled an opportunity-and this was perhaps after all its most valuable aspect-for lonely workers scattered all over the world to meet together face to face with their colleagues in other countries. We had read with interest the publications of many of these colleagues, and had agreed or disagreed with their findings. But at these meetings the dry bones of scientific discussion became clothed with flesh and blood. Friendships were formed which will make future discussions more human. In their arduous and often disappointing labours isolated workers will look back to those strenuous days of fellowship at the Cairo Congress.

An invitation has been received and accepted to hold the next International Congress in Paris in 1943. This is particularly appropriate as the new President of the International Leprosy Association is Prof. Marchoux, of the Pasteur Institute, the well-known authority on leprosy. While some agreements have been reached at Cairo, much more important is the co-ordinated effort which has been set in motion, and which should make it possible, after the next five years, to record steady progress. 